\title{
Renal Cortex
}

National Cancer Institute

\section{Source}

National Cancer Institute. Renal Cortex. NCI Thesaurus. Code C12739.

The outer part of the renal parenchyma beneath the renal capsule. It contains glomeruli and tubules. 